NASA/TM-2004-213291

\title{
Overview of NASA's Pulsed Plasma Thruster Development Program
}

Eric J. Pencil and Hani Kamhawi

Glenn Research Center, Cleveland, Ohio

Lynn A. Arrington

QSS Group, Inc., Cleveland, Ohio 
Since its founding, NASA has been dedicated to the advancement of aeronautics and space science. The NASA Scientific and Technical Information (STI) Program Office plays a key part in helping NASA maintain this important role.

The NASA STI Program Office is operated by Langley Research Center, the Lead Center for NASA's scientific and technical information. The NASA STI Program Office provides access to the NASA STI Database, the largest collection of aeronautical and space science STI in the world. The Program Office is also NASA's institutional mechanism for disseminating the results of its research and development activities. These results are published by NASA in the NASA STI Report Series, which includes the following report types:

- $\quad$ TECHNICAL PUBLICATION. Reports of completed research or a major significant phase of research that present the results of NASA programs and include extensive data or theoretical analysis. Includes compilations of significant scientific and technical data and information deemed to be of continuing reference value. NASA's counterpart of peerreviewed formal professional papers but has less stringent limitations on manuscript length and extent of graphic presentations.

- TECHNICAL MEMORANDUM. Scientific and technical findings that are preliminary or of specialized interest, e.g., quick release reports, working papers, and bibliographies that contain minimal annotation. Does not contain extensive analysis.

- CONTRACTOR REPORT. Scientific and technical findings by NASA-sponsored contractors and grantees.
- CONFERENCE PUBLICATION. Collected papers from scientific and technical conferences, symposia, seminars, or other meetings sponsored or cosponsored by NASA.

- SPECIAL PUBLICATION. Scientific, technical, or historical information from NASA programs, projects, and missions, often concerned with subjects having substantial public interest.

- TECHNICAL TRANSLATION. Englishlanguage translations of foreign scientific and technical material pertinent to NASA's mission.

Specialized services that complement the STI Program Office's diverse offerings include creating custom thesauri, building customized databases, organizing and publishing research results ... even providing videos.

For more information about the NASA STI Program Office, see the following:

- Access the NASA STI Program Home Page at http://www.sti.nasa.gov

- E-mail your question via the Internet to help@sti.nasa.gov

- Fax your question to the NASA Access Help Desk at 301-621-0134

- Telephone the NASA Access Help Desk at 301-621-0390

- Write to:

NASA Access Help Desk

NASA Center for AeroSpace Information 7121 Standard Drive

Hanover, MD 21076 
NASA/TM-2004-213291

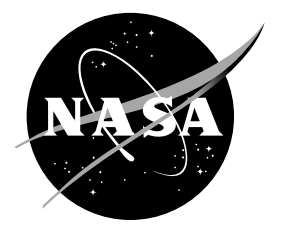

\section{Overview of NASA's Pulsed Plasma Thruster Development Program}

Eric J. Pencil and Hani Kamhawi

Glenn Research Center, Cleveland, Ohio

Lynn A. Arrington

QSS Group, Inc., Cleveland, Ohio

Prepared for the

40th Joint Propulsion Conference and Exhibit

cosponsored by AIAA, ASME, SAE, and ASEE

Fort Lauderdale, Florida, July 11-14, 2004

National Aeronautics and

Space Administration

Glenn Research Center 
Available from

NASA Center for Aerospace Information 7121 Standard Drive

Hanover, MD 21076
National Technical Information Service 5285 Port Royal Road Springfield, VA 22100

Available electronically at http://gltrs.grc.nasa.gov 


\title{
Overview of NASA's Pulsed Plasma Thruster Development Program
}

\author{
Eric J. Pencil and Hani Kamhawi \\ National Aeronautics and Space Administration \\ Glenn Research Center \\ Cleveland, Ohio 44135 \\ Lynn A. Arrington \\ QSS Group, Inc. \\ Cleveland, Ohio 44135
}

\begin{abstract}
NASA's Pulsed Plasma Thruster Program consists of flight demonstration experiments, base research, and development efforts being conducted through a combination of in-house work, contracts, and collaborative programs. The program receives sponsorship from Energetics Project, the New Millennium Program, and the Small Business Innovative Research Program. The Energetics Project sponsors basic and fundamental research to increase thruster life, improve thruster performance, and reduce system mass. The New Millennium Program sponsors the in-orbit operation of the Pulsed Plasma Thruster experiment on the Earth Observing-1 spacecraft. The Small Business Innovative Research Program sponsors the development of innovative diamond-film capacitors, piezoelectric ignitors, and advanced fuels. Programmatic background, recent technical accomplishments, and future activities for each programmatic element are provided.
\end{abstract}

\section{Introduction}

The National Aeronautics and Space Administration's (NASA's) Pulsed Plasma Thruster (PPT) Research and Development program consists of elements supported by the Energetics Project, the New Millennium Program, and the Small Business Innovative Research Program. The Energetics Project is formerly an element of the Aerospace Technology Enterprise's (Code R) Mission and Science Measurement Technology theme, which is being transitioned to the Human \& Robotics Technology theme in the new Office of Exploration at NASA Headquarters. The Energetics Project addresses the technology development through an improved understanding of the fundamental physics and the identification and resolution of design challenges to advance the technology. Current activities include investigating the challenges of improving performance, extending life, and miniaturizing designs. The New Millennium Program has been supporting the flight demonstration of an experiment on the Earth Observing-1 satellite. Recent demonstrations have included the interrogation of the impacts of PPT operation on communications signals, optics sensors, and other spacecraft payloads. The next phase of the demonstration would be planning operations during deorbit maneuvers. The Small Business Innovative Research Program is providing opportunities for small business to develop novel component technologies for future generations of PPTs, including diamond film capacitors, piezoelectric igniters and advanced solid fuels.

\section{Energetics Project}

\section{A. Programmatic Background}

The objectives of the PPT task sponsored by the Energetics Project are to investigate innovative thruster concepts and components which will enable the advancement of PPTs for potential application to a range of spacecraft control functions. These function include attitude control and translation propulsion, momentum management, drag make-up/orbit raising on power limited spacecraft and large space structure dynamic control. The long-term objective of this task has been to advance the PPT state-of-art to effect increased placement in spacecraft systems on NASA, commercial, and military satellites. The efforts have focused on three technology goals for multi-thruster PPT systems, high-efficiency single-axis PPT systems, and micro-PPT concepts. The roadmap for these technology goals is shown in figure 1. 


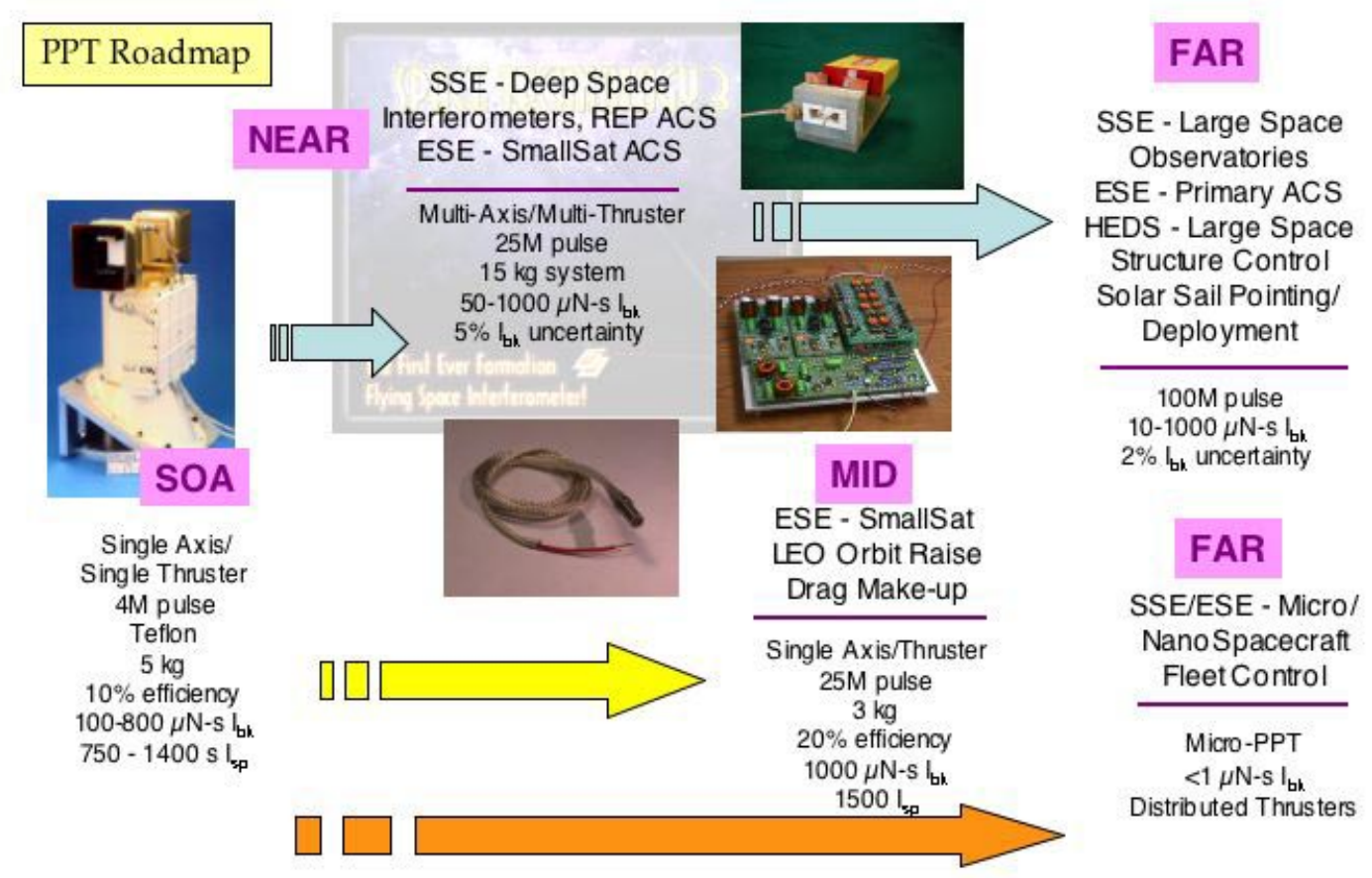

Figure 1.-Roadmap of NASA's Pulsed Plasma Thruster Development Program

Recent technical accomplishments toward these goals under the Energetics Project include:

- the continued life evaluation of breadboard components (energy storage unit, spark plug, discharge initiation unit, and multi-channel power processor unit), which were developed under contract with Unison Industries, Aerojet, and C.U. Aerospace,

- an evaluation of PPT micropulsing as a means to minimize capacitor mass and volume through variable frequency and variable energy PPT operation,

- advanced numerical simulations of a coaxial inverse pinch PPT concept,

- a performance evaluation of alternate propellants in a PPT,

- peer-reviewed publication of PPT plume plasma characterizations, and

- selection as an attitude control system for a concept radioisotope electric propulsion mission.

A detailed description of each of the technical accomplishments is listed in the following section.

\section{B. Recent Technical Accomplishments}

\section{Breadboard Component Life Demonstration}

Future applications of pulsed plasma thrusters will include longer-life, higher-precision, multi-axis thruster configurations, used for applications such as three-axis attitude control systems or high-precision, formation-flying systems. Advanced components, such as a "dry" mica-foil capacitor, a wear-resistant spark plug, a discharge initiation module, and a multi-channel power processing unit (shown in fig. 2) were developed under contract with Unison Industries, General Dynamics, and C.U. Aerospace ${ }^{1}$. These components offered many advantages over the Earth Observing-1 PPT hardware and were evaluated extensively at NASA Glenn Research Center ${ }^{2}$. In order to demonstrate the anticipated life of these components, a life test was initiated at NASA Glenn in the fall of 2001. The breadboard components were 
integrated into a two-nozzle, parallel-axis, laboratory PPT. The laboratory PPT was mounted inside a $1.52-\mathrm{m}$ diameter by $3.05-\mathrm{m}$ tall vertical vacuum chamber, which was evacuated by an isolatable cryogenic pump. The duration of the test runs were limited by many factors including the amount of fuel that can be loaded into the laboratory PPT and the total pumping capacity of the cryogenic pump. These interruptions required that the facility be vented to atmospheric conditions to replace the fuel bar or regenerate the pumping surface. Although the microprocessor in the power processing unit was locking up frequently early in the test phase adjustments to software, filtering, and grounding permitted longer test periods.

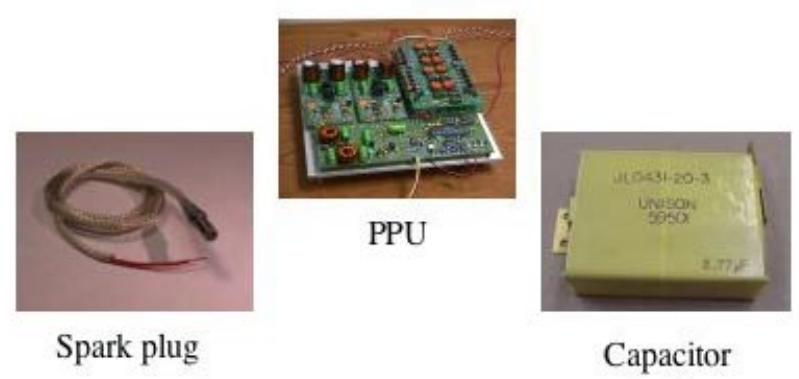

Figure 2.-Composite photograph of breadboard components undergoing life evaluation.

The breadboard component life test has had mixed results. To date the energy storage unit (micafoil capacitor), discharge initiation module, and the power processing unit have successfully been operated for an accumulated 38 million pulses, which exceeds the near-term life requirements for deep-space interferometry demonstrator missions. The rated life for the energy storage unit was anticipated to be 45 million pulses. The spark plug has not been as successful. Presently the spark plug life has been limited typically to 1 to 4 million pulses. Several concurrent phenomena have bounded spark plug life. To remove fluorocarbon soot formation on the surface of the spark plug, an operation called pulse clearing was performed. Pulse clearing offered some life extension, however, the test hardware ultimately needed to be cleaned mechanically after the accumulation of about 1 to 2 million pulses. Although the mechanical cleaning process did not rigorously test the components in a manner consistent with space operations, it has revealed a concurrent life-limiting issue with the spark plugs, which was significant erosion of the nickel outer electrode. It should be noted that the iridium inner electrode has survived the same operation without erosion. As a result of this observation, a spark plug with both electrodes made from iridium, has been designed, fabricated, and implemented into the life test.

\section{Micropulsing Evaluation}

In order to reduce mass and volume, the breadboard component designs lowered discharge energy and increased the pulse repetition rate range. Although this maintained the same thruster power levels, there was an underlying assumption that there would be no penalties in thruster performance. An evaluation of the impact of micropulsing on thruster performance has been investigated ${ }^{3}$. The test matrix included variation in discharge energy, capacitance, and pulse repetition rate to cover the thruster power throttling range. Thruster performance was quantified via power, propellant mass loss, and thrust measurements. When capacitance is varied the impact on impulse bit is shown for each discharge energy level in Figure 3. The trend was different for efficiency and specific impulse. When the thruster power was held constant, both efficiency and specific impulse decreased as the capacitance was lowered. 


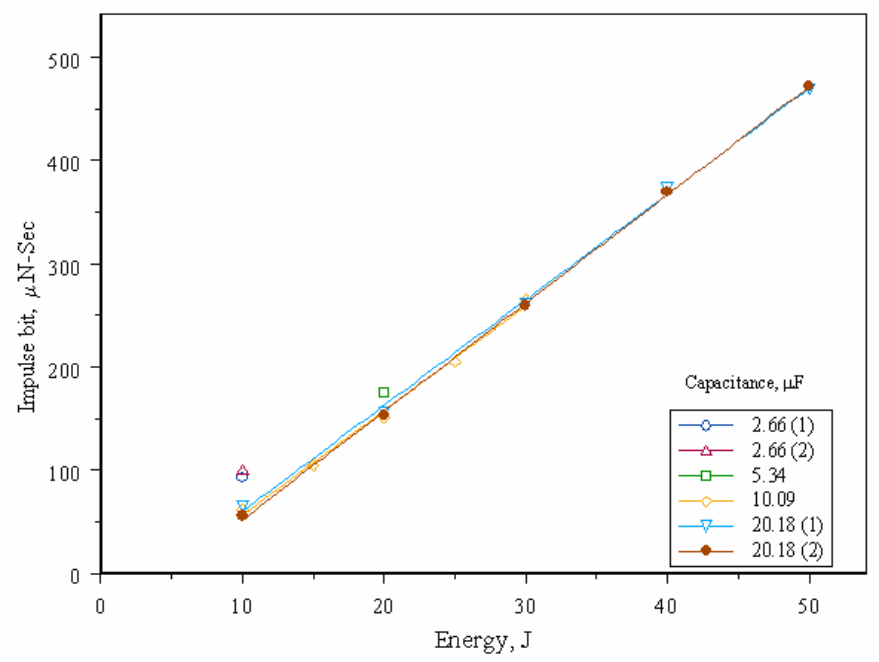

Figure 3.-Impulse bit as a function of discharge energy for various capacitances.

\section{Coaxial Inverse Pinch PPT Numerical Simulations}

Coaxial inverse-pinch PPT numerical simulations indicated that an axisymmetric discharge current distribution on the polytetrafluoroethylene (PTFE) surface permitted the attainment of high peak currents while limiting PTFE surface temperatures below the decomposition temperature. This limited post-pulse evaporation and macro-particle evolution. ${ }^{4,5,6}$ Recent numerical simulations using the MACH2 code were performed to interrogate the effects of background pressure and PTFE temperature boundary conditions on the magnitude of ablated mass. In general, results indicated that operating at a low background pressure (less than 0.01 mTorr) caused elevated temperatures in the PTFE solid in comparison with higher background pressures, and as such may initiate macro-particle evolution from the propellant surface. Figure 4 shows the MACH2 8-block computational domain and current contours at peak temperature for a coaxial inverse-pinch PPT operating with a background pressure less than $0.01 \mathrm{mTorr}$ at 20 joule.
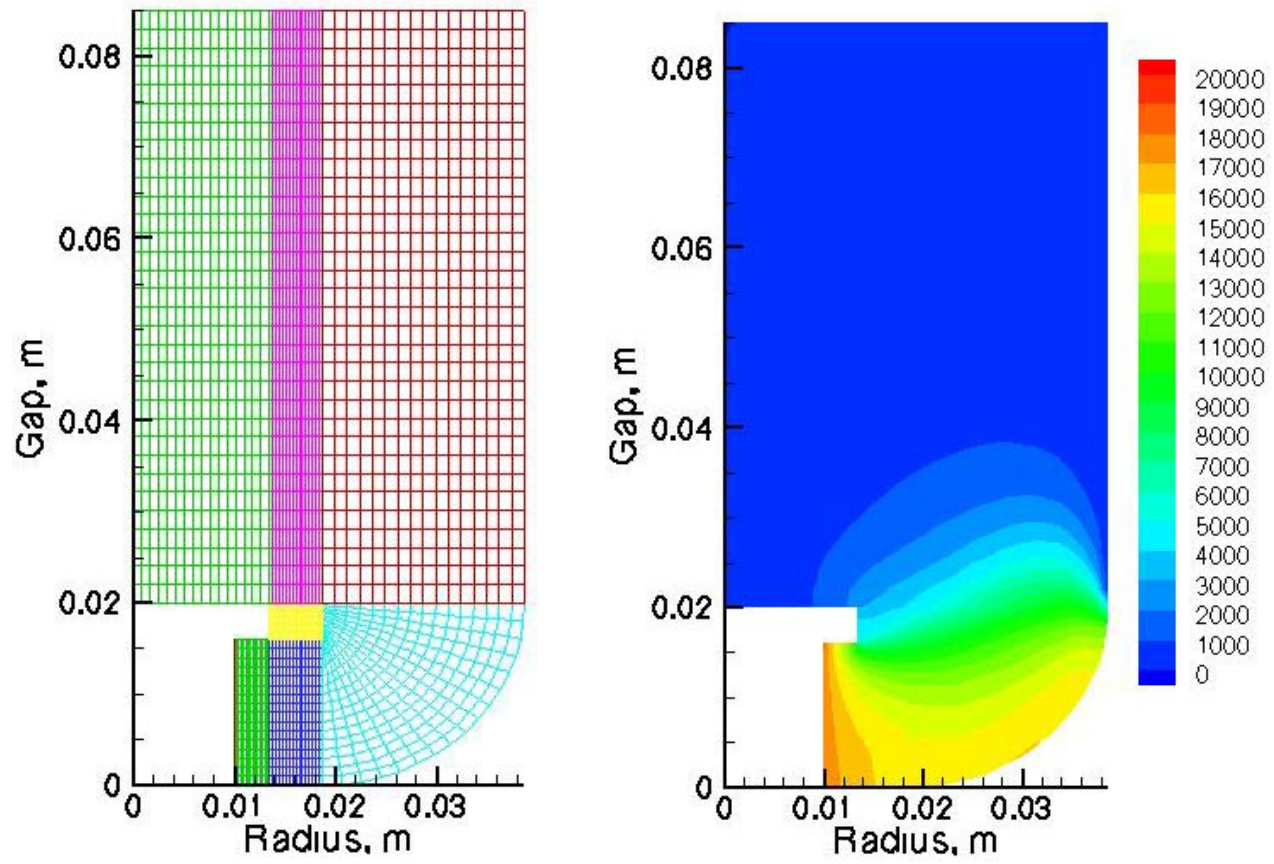

Figure 4.-MACH2 computational domain and simulation results of current contours at 20 joule. 


\section{Alternate Fuel Evaluation}

Additional in-house research has focused on the performance evaluation of additives to PTFE propellants. Research indicates that small amounts of carbon added to PTFE significantly reduced propellant ablation rates, while marginally changing thrust. The improvements over nominal PTFE depended on several factors including discharge energy ${ }^{7}$, electrode geometry ${ }^{8}$, and propellant composition ${ }^{9}$. For discharge energies ranging from 40 to 140 joules, the propellant ablation rates were about 20 percent lower for 2\%-carbon PTFE as compared to nominal PTFE with no change to the impulse bit generated. The net result was a 3 percent improvement to thruster efficiency and a $26 \%$ to $33 \%$ improvement to specific impulse in these cases as shown in figure 5. For discharge energies ranging from 5 to 60 joules, the propellant ablation rates were about 20 percent lower for $2 \%$-carbon PTFE as compared to nominal PTFE with no change to the impulse bit generated. The net result was an improvement up to 6 percent to thruster efficiency. For discharge energies between 5 and 10 joules, a high thrust-to-power configuration (large gap to length ratios) demonstrated that a 50 percent reduction in propellant ablation rates could be achieved with the addition of $2 \%$ carbon to PTFE. The net result was $50 \%$ increase in specific impulse for the conditions tested.

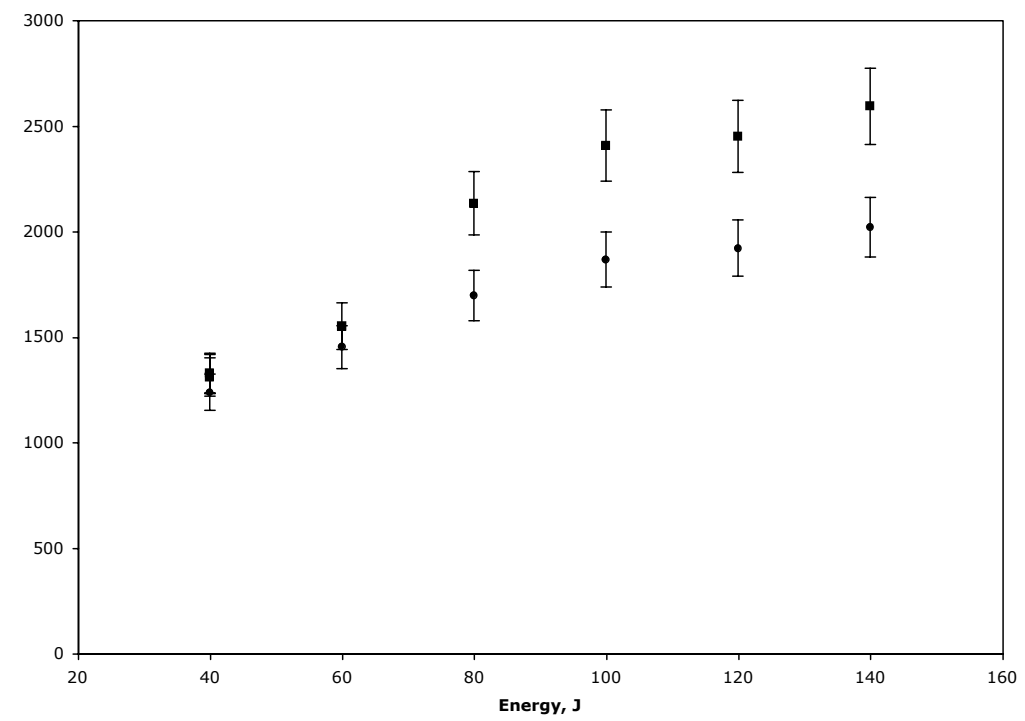

Figure 5.-Specific impulse comparison of 2\%-carbon PTFE to nominal PTFE.

\section{PPT Plasma Characterization}

A current-mode quadruple and triple langmuir probe methods were developed and used to measure electron temperature, electron density, and the ratio of ion speed to most probable thermal speed in a PPT plume ${ }^{10}$. The novel approach of measuring the currents in the biased probe leads increased signal to noise significantly during the first few microseconds of the PPT discharge. Also the issue of voltage fluctuations due to pickup of electromagnetic emissions on the ungrounded probe leads was eliminated. The theory for the current collection method was developed in detail ${ }^{11}$. The experimental results of the plasma characterization include the insight that electron temperatures ranged in excess of 10 electron volts during the rise of the discharge current, but typically less than 5 electron volts for the rest of the pulse. Representative plots of probe/discharge currents, electron temperature $\left(T_{e}\right)$, electron number density $\left(n_{e}\right)$, and ratio of ion speeds $\left(\mathrm{S}_{\mathrm{i}}\right)$ are shown in figure 6 . In addition electron density maps across the plume were collected at several discharge energies. 


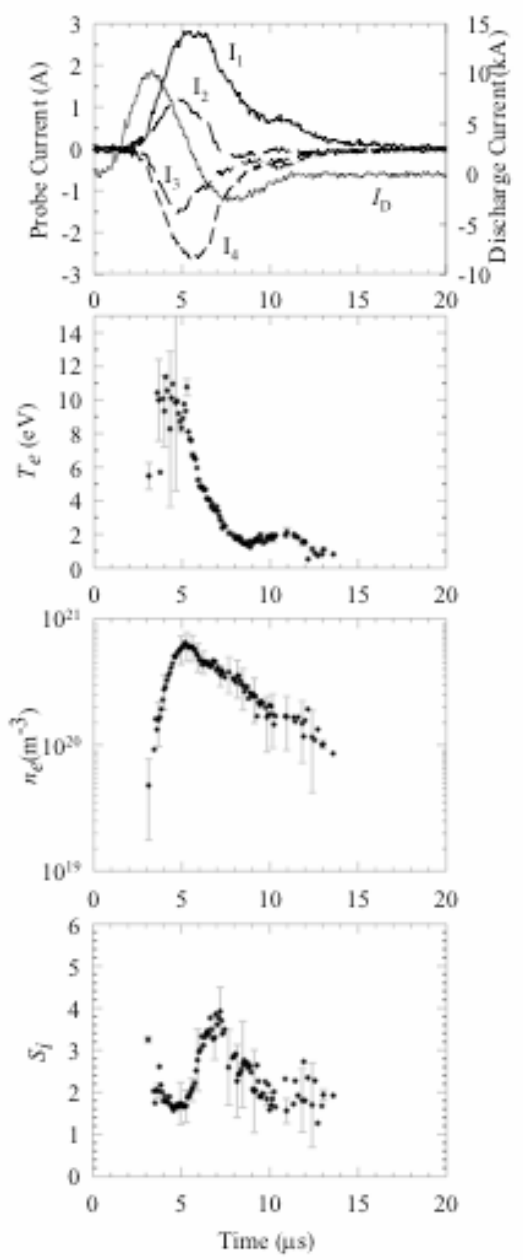

Figure 6.-Discharge current, quadruple-Langmuir-probe currents and resultant plasma properties.

\section{Attitude Control Systems for Radioisotope Electric Propulsion Missions}

A design study of Radioisotope Electric Propulsion (REP) missions to Neptune orbiters was conducted $^{12}$. The spacecraft concept design is shown in figure 7. A comparison was made to solar electric propulsion (SEP) stage/aerocapture scenarios. The REP approach increased power available for scientific instrumentation after primary ion thruster operation with comparable trip times as compared to the baseline approach. The attitude control system (ACS) of this REP design was constrained to last over 14 years and use less than $100 \mathrm{~W}$ of power. PPTs met the design constraints, provided reasonable roll-control and as a result were selected as the baseline ACS. The Energetics Project PPT task provided definition of the PPT ACS subsystem to the spacecraft concept study.

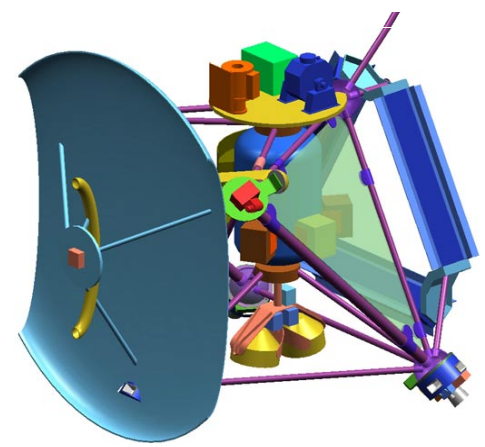

Figure 7.-REP spacecraft conceptual design using PPTs as the baseline attitude control system. 


\section{Future Activities}

The basic research and development activities conducted under the sponsorship of the Energetics Project will not continue beyond FY04. Alternate sources of funding are being sought in Space and Earth Science Enterprises.

\section{New Millennium Program's Earth Observing 1 PPT Flight Demonstration}

\section{A. Programmatic Background}

The Earth Observing-1 PPT experiment was implemented by the New Millennium Program to demonstrate advances in PPT technology ${ }^{13}$. Advances in materials, electrical components, and circuit card technologies provided potential to significantly reduce thruster dry mass from prior flight thrusters. A flight experiment was designed to incorporate those advances in a protoflight thruster and demonstrate pitch axis control and momentum management on a small, low Earth orbit science spacecraft ${ }^{14}$. Results of this flight experiment have validated usage of PPT technology in spacecraft systems.

\section{B. Recent Technical Accomplishments}

The Pulsed Plasma Thruster (PPT) mounted on the Earth Observing-1 spacecraft was operated successfully in orbit in $2002^{15}$. The two-axis thruster system is fully incorporated in the attitude determination and control system and is being used to automatically counteract disturbances in the pitch axis of the spacecraft.

Since the first successful functionality demonstration, the impacts of thruster emissions on communication systems have been interrogated. X-band and S-band communications data packages were transmitted during thruster operation and analyzed for data corruption. A summary of the results from these tests is listed in table 1. The analysis has verified that there was no measurable increase in bit error rates during thruster operation. The benign interactions reduce user concerns and pave the way for electric propulsion applications on future earth imaging satellites ${ }^{16}$.

Table 1.-Results of EO-1 Communications Compatibility Test. ${ }^{16}$

\begin{tabular}{|c|c|c|c|c|c|c|}
\hline Pass & $\begin{array}{c}\text { Time } \\
\text { (DOY:HH } \\
\text { :MM) }\end{array}$ & $\begin{array}{l}\text { Ground } \\
\text { Station }\end{array}$ & Band & $\begin{array}{c}\text { PPT } \\
\text { Control }\end{array}$ & $\begin{array}{l}\text { Bit } \\
\text { Error } \\
\text { Count }\end{array}$ & Comments \\
\hline 1 & $246: 06: 23$ & PF1 & $X \& S$ & No & 123 & \\
\hline 2 & 246:08:01 & AGS & $\mathrm{S}$ & No & 456 & \\
\hline 3 & 246:16:36 & LGS & $\mathrm{X}$ & No & 789 & \\
\hline 4 & 246:18:14 & LGS & $\mathbf{X}$ & Yes & 789 & $\begin{array}{l}\text { Multiple files. Sequence break on 1st } \\
\text { image (pre-image dark calibration) }\end{array}$ \\
\hline 5 & 246:19:47 & AGS & $\mathbf{X \& S}$ & Yes & 444 & $\begin{array}{l}\text { Multiple files. } 6 \text { sequence breaks on the } \\
\text { 3rd file (image), } 1 \text { sequence break on the } \\
\text { 4th file (image) and } 3 \text { sequence breaks on } \\
\text { the 6th file (post-image dark calibration) }\end{array}$ \\
\hline 6 & 246:21:26 & PF1 & X\&S & Yes & 666 & Multiple files, no breaks \\
\hline 7 & 246:23:04 & PF1 & $\mathbf{X \& S}$ & Yes & 777 & Multiple files, no breaks \\
\hline 8 & 247:02:16 & AGS & $\mathrm{S}$ & No & 898 & \\
\hline 9 & 247:05:41 & PF1 & $\mathrm{S}$ & No & 676 & \\
\hline 10 & 247:13:12 & HGS & $\mathrm{X}$ & No & 666 & Multiple files, no breaks \\
\hline 11 & 248:02:49 & LGS & $\mathrm{X}$ & No & & \\
\hline
\end{tabular}

\section{Future Activities}

Although no near-term activities have been defined for the EO-1 experiment, additional tests are being planned during spacecraft deorbit. As a spacecraft nears the end of its useful life, "high risk" maneuvers such as rolling the spacecraft about its pitch axis as a means to calibrate thruster performance 
against ground test data, can become acceptable risk events to spacecraft operators. Additional tests will be defined as the spacecraft nears the end of its useful life.

\section{Small Business Innovative Research (SBIR) Program}

\section{A. Programmatic Background}

Opportunities for small business exist under the SBIR Program to develop future generations of PPT components. Examples of these efforts include the development of diamond film capacitors, piezoelectric ignitors, and advanced PPT fuels. The following section outlines recent accomplishments under these development contracts.

\section{B. Diamond Film Capacitors}

Titan Industries (formerly Jaycor Industries), in collaboration with Vanderbilt University and Aerojet, has developed diamond film capacitors under a Phase II contract to the NASA Small Business Innovative Research Program. The purpose of the contract is to develop high energy density capacitors using chemical vapor deposited (CVD) diamond films as the dielectric material. It is expected that the diamond film capacitor would by a factor of ten, decrease the discharge time, decrease the heating and increase the useful lifetime of the capacitor. These capacitors offer advancements in packaging over conventional capacitor technologies. The targeted operating characteristics of the capacitor developed in Phase II are as follows:

Table 2.-Diamond film capacitor operating characteristics

\begin{tabular}{|l|l|}
\hline Operating Voltage & 4,000 volts \\
\hline Repetition Rates & $>1000$ cycles $/ \mathrm{sec}$ \\
\hline Operational Temperature & -70 to $155^{\circ} \mathrm{C}$ \\
\hline Energy Density & $>1 \mathrm{~J} / \mathrm{g}$ or $>3.5 \mathrm{~J} / \mathrm{cm}^{3}$ \\
\hline Capacitance & 0.125 microfarads \\
\hline Energy Storage & 1 Joule \\
\hline Lifetime & 30 years \\
\hline
\end{tabular}

In addition Vanderbilt University has successfully fabricated diamond dielectric with high resistance on both silicon and molybdenum. The resulting leakage currents are similar to or lower than comparable commercially available capacitors. Figure 8 shows a sample diamond dielectric film capacitor.

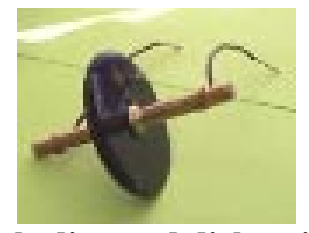

Figure 8.-Sample diamond dielectric film capacitor.

\section{Piezoelectric Ignitors}

Face Electronics, Inc. is investigating the manufacturing and development of piezoelectric materials for application to ignition circuits in a pulsed plasma thruster. During Phase I Face Electronics demonstrated the feasibility of developing a high voltage initiation circuit able to deliver sparks up to $15 \mathrm{kV}$ and over $5 \mathrm{~W}$ in power. The ignition scheme utilizes piezoelectric based ignition schemes. The breadboard electronics are shown in figure 9 (a quarter provides the scale). In Phase II, Face Electronics plans to optimize the circuit design for PPT propulsion systems used in small satellites which weigh less than 20 kilograms, integrate controller circuitry with the power processing circuitry, optimize booster circuit output, integrate the components into a single housing unit, which would integrate with an appropriately sized PPT. 


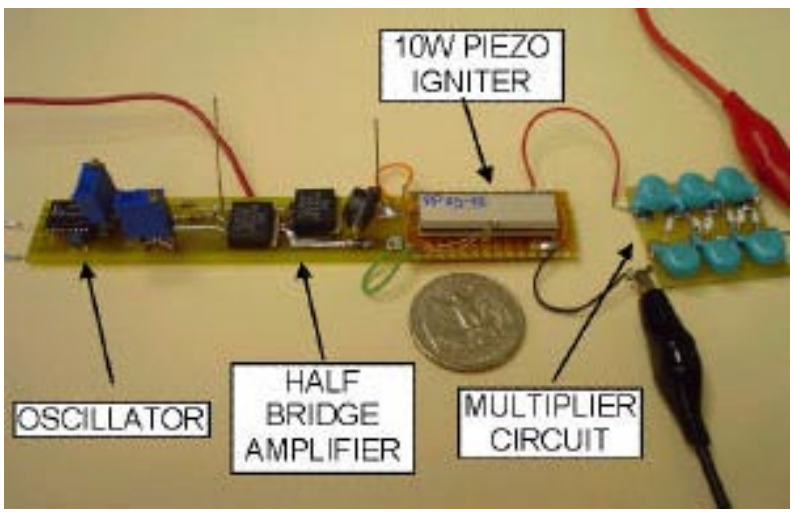

Figure 9.-Breadboard piezoelectric ignition system.

\section{Advanced PPT fuels}

ET Materials, LTD, is working under a Phase I SBIR contract to investigate innovative formulations of electrically ignitable materials, which may offer advantages over existing PPT fuels. ET Materials has developed several formulations under its Phase I contract and has completed performance tests on a thrust stand at Aerojet. The advantages that these formulations offer are under evaluation at present, but could include fuel decomposition to non-condensing constituents and improved electrothermal thrust component generation.

\section{E. Future Activities}

Like with any SBIR development contract, other sources of funding (non-SBIR) will be investigated for advancing these components to a higher Technology Readiness Level for future generations of PPTs.

\section{Summary}

The Pulsed Plasma Thruster development program by NASA GRC during recent years under the sponsorship of the Energetics Project, New Millennium Program, and the Small Business Innovative Research Program was described. Programmatic background, recent technical accomplishments and future activities were provided. Under the sponsorship of Energetics, basic and fundamental research was conducted to evaluate the life of the advanced breadboard components, to evaluate the effectiveness of micropulsing, to understand coaxial inverse pinch thruster operation through numerical models, to evaluate the performance of alternate propellants, and to understand plume expansion through the plasma characterization. Inputs to a conceptual spacecraft design of a radioisotope electric propulsion Neptune orbiter led to the PPTs being selected as the baseline configuration for attitude control system. Under the sponsorship of New Millennium Program, EO-1 flight operations have demonstrated benign interactions with other spacecraft systems, adding to an extensive database for future applications. The SBIR program is investing innovative concepts, like diamond-film capacitors, piezoelectric ignitors, and advanced fuels, which promise reductions in system mass and volume in future generations of PPTs.

\section{References}

${ }^{1}$ Benson, S.W., and Frus, J.R. "Advanced Pulsed Plasma Thruster Electrical Components," AIAA-20013894, 36th Joint Propulsion Conference, Salt Lake City, UT, July 2001.

${ }^{2}$ Pencil, E.J., Arrington, L.A., and Carter, T., "Evaluation of Pulsed Plasma Thruster Breadboard Electrical Components," AIAA-2001-3898, 36th Joint Propulsion Conference, Salt Lake City, UT, July 2001.

${ }^{3}$ Arrington, L.A., "Evaluation of Pulsed Plasma Thruster Micropulsing," AIAA-2004-3458, 40th Joint Propulsion Conference, Fort Lauderdale, FL, July 2004. 
${ }^{4}$ Mikellides, I.G., "Theoretical Modeling and Optimization of Ablation-Fed Pulsed Plasma Thruster," Ph.D dissertation, Columbus, Ohio Sept. 1999.

${ }^{5}$ Kamhawi, H. Mikelides, P.G., Turchi, P.J., "Experimental and Theoretical Investigation of a Coaxial Inverse Pinch Pulsed Plasma Thruster," IEPC-01-162, Proceedings of the 27th International Electric Propulsion Conference, Pasadena, CA, October 2001.

${ }^{6}$ Kamhawi, H., "Experimental and Theoretical Investigation of Pulsed Plasma Thrusters," Ph.D dissertation, Columbus, Ohio June 2002.

${ }^{7}$ Pencil, E.J., and Kamhawi, H., "Alternate Fuel Evaluation in a 100 Joule Class Pulsed Plasma Thruster," AIAA-2003-5171, 39th Joint Propulsion Conference, Huntsville, AL, July 2003.

${ }^{8}$ Kamhawi, H., Pencil, E.J., and Haag, T.W., "High Thrust-to-Power Parallel-Rail Pulsed Plasma Thruster Design,” AIAA-2002-3975, 38th Joint Propulsion Conference, Indianapolis, IN, July 2002.

${ }^{9}$ Pencil, E.J., Kamhawi, H., Arrington, L.A., and Warren, W.B., "Evaluation of Alternate Propellants for Pulsed Plasma Thrusters," IEPC-01-047, Proceedings of the 27th International Electric Propulsion Conference, Pasadena, CA, October 2001.

${ }^{10}$ Gatsonis, N.A., Zwahlen, J., Wheelock, A, Pencil, E.J., and Kamhawi, H., "Pulsed Plasma Thruster Plume Investigation Using a Current-Mode Quadruple Probe Method," Journal of Propulsion and Power, Vol. 20, No.2, pp 243-254, March-April 2004.

${ }^{11}$ Gatsonis, N.A., Byrne, L., Zwahlen, J., Pencil, E.J., and Kamhawi, H., "Current-Mode Triple and Quadruple Langmuir Probe Methods with Application to Flowing Pulsed Plasmas," accepted for publication in IEEE Transactions on Plasma Science, August 2004 edition.

${ }^{12}$ Fiehler, D.I., and Oleson, S.R., "Neptune Orbiters Utilizing Solar and Radioisotope Electric Propulsion," AIAA-2004-3978, 40th Joint Propulsion Conference, Fort Lauderdale, FL, July 2004.

${ }^{13}$ Benson, S.W., Arrington, L.A., Hoskins, W.A., and Meckel, N.J., "Development of a PPT for the EO-1 Spacecraft," AIAA-1999-2276, 34th Joint Propulsion Conference, Los Angeles, CA, June 1999.

${ }^{14}$ Zakrwski, C.M., Sanneman, P., Hunt, T., and Blackman, K., "Design of the EO-1 Pulsed Plasma Thruster Attitude Control System," AIAA-2001-3637, 36th Joint Propulsion Conference, Salt Lake City, UT, July 2001.

${ }^{15}$ Zakrwski, C.M., Benson, S.W., Sanneman, P., and Hoskins, W.A, "On-Orbit Testing of the EO-1 Pulsed Plasma Thruster,” AIAA-2002-3973, 38th Joint Propulsion Conference, Indianapolis, IN, July 2002.

${ }^{16}$ Hoskins, W.A., Rayburn, C., and Sarmiento, C.J., "Pulsed Plasma Thruster Electromagnetic Compatibility: History, Theory and the Flight Validation on EO-1," AIAA-2003-5016, 39th Joint Propulsion Conference, Huntsville, AL, July 2003. 
Public reporting burden for this collection of information is estimated to average 1 hour per response, including the time for reviewing instructions, searching existing data sources, gathering and maintaining the data needed, and completing and reviewing the collection of information. Send comments regarding this burden estimate or any other aspect of this collection of information, including suggestions for reducing this burden, to Washington Headquarters Services, Directorate for Information Operations and Reports, 1215 Jefferson Davis Highway, Suite 1204, Arlington, VA 22202-4302, and to the Office of Management and Budget, Paperwork Reduction Project (0704-0188), Washington, DC 20503.

\begin{tabular}{|l|l|l}
\hline 1. AGENCY USE ONLY (Leave blank) & $\begin{array}{c}\text { 2. REPORT DATE } \\
\text { September } 2004\end{array}$ & $\begin{array}{r}\text { 3. REPORT TYPE AND DATES COVERED } \\
\text { Technical Memorandum }\end{array}$ \\
\hline
\end{tabular}

4. TITLE AND SUBTITLE 5. FUNDING NUMBERS

Overview of NASA's Pulsed Plasma Thruster Development Program

6. AUTHOR(S)

WBS-22-319-20-D2

Eric J. Pencil, Hani Kamhawi, and Lynn A. Arrington

7. PERFORMING ORGANIZATION NAME(S) AND ADDRESS(ES)

8. PERFORMING ORGANIZATION

National Aeronautics and Space Administration

John H. Glenn Research Center at Lewis Field

Cleveland, Ohio 44135-3191

REPORT NUMBER

E-14738

9. SPONSORING/MONITORING AGENCY NAME(S) AND ADDRESS(ES)

National Aeronautics and Space Administration

Washington, DC 20546-0001

10. SPONSORING/MONITORING

AGENCY REPORT NUMBER

NASA TM-2004-213291

AIAA-2004-3455

11. SUPPLEMENTARY NOTES

Prepared for the 40th Joint Propulsion Conference and Exhibit cosponsosred by AIAA, ASME, SAE, and ASEE,

Fort Lauderdale, Florida, July 11-14, 2004. Eric J. Pencil and Hani Kamhawi, Glenn Research Center;

Lynn A. Arrington, QSS Group, Inc., 21000 Brookpark Road, Cleveland, Ohio 44135. Responsible person,

Eric Pencil, organization code 5430, 216-977-7463.

12a. DISTRIBUTION/AVAILABILITY STATEMENT

12b. DISTRIBUTION CODE

Unclassified - Unlimited

Subject Category: 22

Distribution: Nonstandard

Available electronically at http://gltrs.grc.nasa.gov

This publication is available from the NASA Center for AeroSpace Information, 301-621-0390.

13. ABSTRACT (Maximum 200 words)

NASA's Pulsed Plasma Thruster Program consists of flight demonstration experiments, base research, and development efforts being conducted through a combination of in-house work, contracts, and collaborative programs. The program receives sponsorship from Energetics Project, the New Millennium Program, and the Small Business Innovative Research Program. The Energetics Project sponsors basic and fundamental research to increase thruster life, improve thruster performance, and reduce system mass. The New Millennium Program sponsors the in-orbit operation of the Pulsed Plasma Thruster experiment on the Earth Observing-1 spacecraft. The Small Business Innovative Research Program sponsors the development of innovative diamond-film capacitors, piezoelectric ignitors, and advanced fuels. Programmatic background, recent technical accomplishments, and future activities for each programmatic element are provided.

\section{SUBJECT TERMS}

Electric propulsion; Pulsed plasma thrusters; Auxilliary propulsion; Electromagnetic propulsion

17. SECURITY CLASSIFICATION OF REPORT

Unclassified
18. SECURITY CLASSIFICATION OF THIS PAGE

Unclassified
19. SECURITY CLASSIFICATION OF ABSTRACT

Unclassified
15. NUMBER OF PAGES

16

16. PRICE CODE

20. LIMITATION OF ABSTRACT

Standard Form 298 (Rev. 2-89)

Prescribed by ANSI Std. Z39-18 298-102 

